\title{
Germ Cell Tumor Presenting with Precocious Puberty in a Girl in United Arab Emirates
}

\author{
Asim Noor Rana ${ }^{a}$ Hani Humad ${ }^{a}$ Aeman Muhammad Asif ${ }^{b}$ Dana Ghannam ${ }^{b}$ \\ Nadia Nadeem ${ }^{b}$ \\ ${ }^{a}$ Dubai Health Authority, Dubai Hospital, Dubai, United Arab Emirates; ${ }^{b}$ Dubai Medical College, Dubai, \\ United Arab Emirates
}

\section{Keywords}

Mixed germ cell tumor · Embryonal cancer · Yolk sac tumor/endodermal sinus tumor . Precocious puberty .

Multidisciplinary team

\begin{abstract}
We herein report a rare case of malignant mixed germ cell tumor comprising both an embryonal carcinoma $(60 \%)$ and a yolk sac tumor (40\%). A 7-year-old girl presented to the emergency department with persistent vaginal bleeding, abdominal pain, and vomiting. A CT scan of the pelvis and abdomen revealed a huge pelvic mass, $16 \times 16 \times 8 \mathrm{~cm}$, arising from the left ovary and extending into the upper abdomen and displacing bowel loops to the sides. The mass was lobulated and heterogeneously enhancing. Initial investigations revealed raised values of beta-human chorionic gonadotrophin (B-hCG) and alpha-fetoprotein (AFP). She underwent a laparotomy and a left salphingo-oophorectomy. Histopathology of the excised mass revealed a malignant mixed germ cell tumor comprising both an embryonal carci-
\end{abstract}

noma (60\%) and a yolk sac tumor (40\%). Following surgery, she was started on adjuvant chemotherapy based on the MAKEI 96 protocol and was given 4 cycles of PEl chemotherapy (cisplatin, etoposide, and ifosfamide). Multidisciplinary team management consisting of careful initial surgery with adequate staging biopsies followed by combination chemotherapy and endocrinological evaluation and treatment can greatly improve the prognosis of these patients.

(c) 2020 The Author(s)

Published by S. Karger AG, Basel

\section{Introduction}

Germ cell tumors (GCTs) are benign or malignant tumors arising from germ cells. Since germ cells are usually located inside ovaries and testicles, they are the most common sites for GCTs; however, GCTs may be found on extragonadal sites. Ovarian GCTs arise from primordial germ cells of the ovary. They are mostly benign but $1-2 \%$ may be malignant [1]. They arise primarily in young

\begin{tabular}{ll}
\hline KARGER & $\begin{array}{l}\text { Ka 2020 The Author(s) } \\
\text { Published by S. Karger AG, Basel }\end{array}$ \\
E-Mail karger@karger.com & $\begin{array}{l}\text { This article is licensed under the Creative Commons Attribution- } \\
\text { NonCommercial-NoDerivatives 4.0 International License (CC BY- } \\
\text { NC-ND) (http://www.karger.com/Services/OpenAccessLicense). } \\
\text { www.karger.com/dmj }\end{array}$ \\
& $\begin{array}{l}\text { Usage and distribution for commercial purposes as well as any dis- } \\
\text { tribution of modified material requires written permission. }\end{array}$
\end{tabular}


women between 10 and 30 years of age [2]. Malignant ovarian tumors are a very rare cause of precocious puberty. Precocious puberty is when physical and hormonal signs of pubertal development appear earlier than the normal age of puberty - which is 8 years in girls and 9 years in boys [3].

\section{Case Presentation}

A 7-year-old girl presented to the emergency room with a 3-day history of abdominal pain and vomiting. She had abdominal distension for 2 days and vaginal bleeding for 5 days. According to her mother, she had breast development at the age of 4 years and axillary and pubic hair 2 months prior to admission. She also noticed a rapid increase in height. She was not on any regular medications and had no other chronic illness. She was studying in grade 2 and performing well. She is one of five healthy children. There was no family history of cancers or precocious puberty; however, one of her maternal aunts had menarche at the age of 9 years.

Upon examination, she was overweight (BMI $25.9 \mathrm{~kg} /$ $\mathrm{m}^{2}$ ) and not dysmorphic. She had a distended abdomen with diffuse tenderness and a palpable suprapubic mass measuring around $15 \times 7 \mathrm{~cm}$ and reaching up to the epigastrium. Tanner stage of breast and pubic hair were stage 4 and 3 , respectively.

Initial investigations showed very high tumor markers - beta-human chorionic gonadotrophin (B-hCG) $104,275 \mathrm{mlU} / \mathrm{mL}$, alpha-fetoprotein (AFP) $>30,000$, and estradiol 779.0 pmol/L. Bone age (Fig. 1) corresponded to the female standard of 10 years. Abdominal ultrasound revealed a huge soft tissue mass (approx. $15 \mathrm{~cm} \times$ $10 \mathrm{~cm}$ ) in the lower abdomen. Proximally, the mass appeared solid from right to left flanks but separated from the kidneys, while distally, towards the uterus, it had a heterogeneous echotexture, appearing lobulated with blood vessels in between. A provisional diagnosis of an ovarian teratoma was made, and a CT was immediately arranged.

A CT scan of the pelvis and abdomen was carried out (Fig. 2) which revealed the following: "A huge pelvic mass is seen arising from the left ovary and extending into upper abdomen and displacing bowel loops to the sides. The mass is lobulated and heterogeneously en-

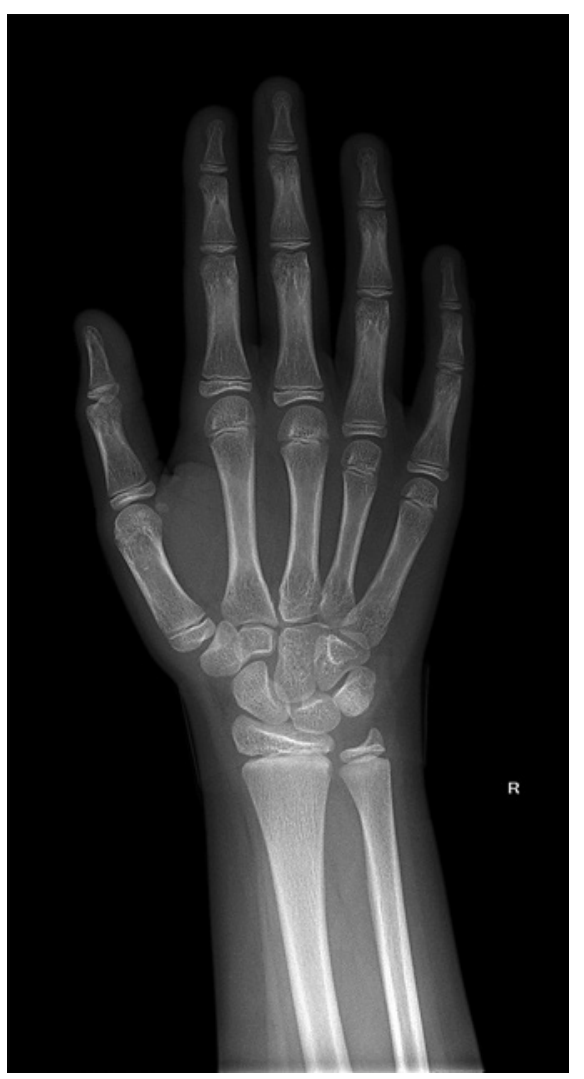

Fig. 1. X-ray of the right hand showing bone age.

Fig. 2. Abdominal CT.
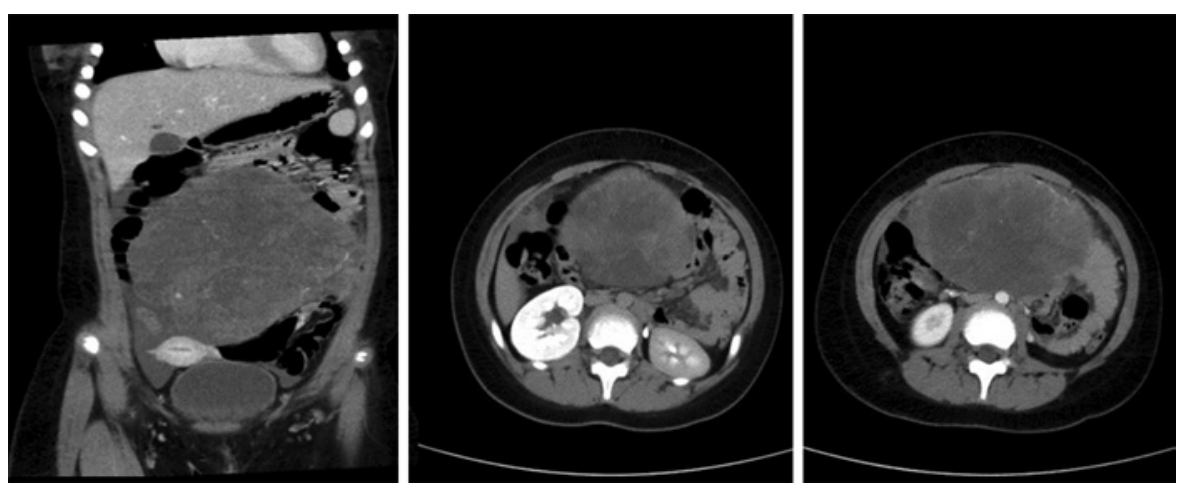
hancing. It was measuring about $16 \times 16 \times 8 \mathrm{~cm}$ in CC, TRANS and AP diameters. The mass is not infiltrating into adjacent tissue. However, it causes mild compression effect on the right ureter with mild hydronephrosis and hydroureter. The uterus is hypertrophic, however with petite intrauterine cavity without signs of the pregnancy."

The next day, she underwent laparotomy and a left salphingo-oophorectomy; the excised mass weighed 1.215 $\mathrm{kg}$. In addition, a right fimbrial cyst was found and excised. Histopathology showed a malignant mixed GCT comprising an embryonal carcinoma (60\%) and a yolk sac tumor (40\%). The capsular surface of the ovary was intact (pT1a). There were no complications following surgery, and the tumor markers B-hCG and AFP reduced drastically (Fig. 3).

Since the tumor was stage 1a, the girl was kept under close observation only as recommended by the protocol guidelines. As part of multidisciplinary team management, she was seen by our pediatric endocrinologist and advised to do an LHRH stimulation test after surgical resection of the tumor and to consider starting GnRH agonist to arrest her precocious puberty and to preserve her future fertility. The LHRH test came back as positive, hence she was started on Decapeptyl $11.25 \mathrm{mg}$ i.m. once every 3 months.

At 3 months postsurgery, on a routine visit to the hemato-oncology clinic, she complained of urinary incontinence. Upon admission for workup, she was found to have increasing tumor markers: B-hCG and AFP started rising $(\mathrm{B}-\mathrm{hCG}=1,599 \mathrm{mIU} / \mathrm{mL}, \mathrm{AFP}=47.6 \mathrm{IU} / \mathrm{mL})$, hence she was admitted for staging consisting of contrast CT scan of the chest, abdomen, and pelvis, bone scan, creatinine, and hearing screen.

The CT scan (Fig. 4) showed no residual or recurrent masses at the operative site. Left para aortic multiple amalgamated enlarged lymph nodes were observed, measuring collectively about $27 \times 56 \times 50 \mathrm{~mm}$ in maximum dimensions, displaying necrotic center and faint marginal enhancement and numerous subcentimetric mesenteric lymph nodes.

Decapeptyl was stopped during chemotherapy and planned to restart again after recovery of myelosuppression. We started chemotherapy based on the MAKEI 96 protocol consisting of 4 cycles of PEI chemotherapy (cisplatin, etoposide and ifosfamide). Her chemotherapy was complicated by 3 episodes of febrile neutropenia, frequent vomiting, and constipation. She also needed blood transfusions twice in this period.

\section{Discussion}

Malignant ovarian tumors (which account for $1 \%$ of childhood cancers [4]) are a very rare cause of peripheral precocious puberty (PPP); $8 \%$ of all cases of malignant ovarian GCTs show a combination of two or more components. The most common combination is that of dys-

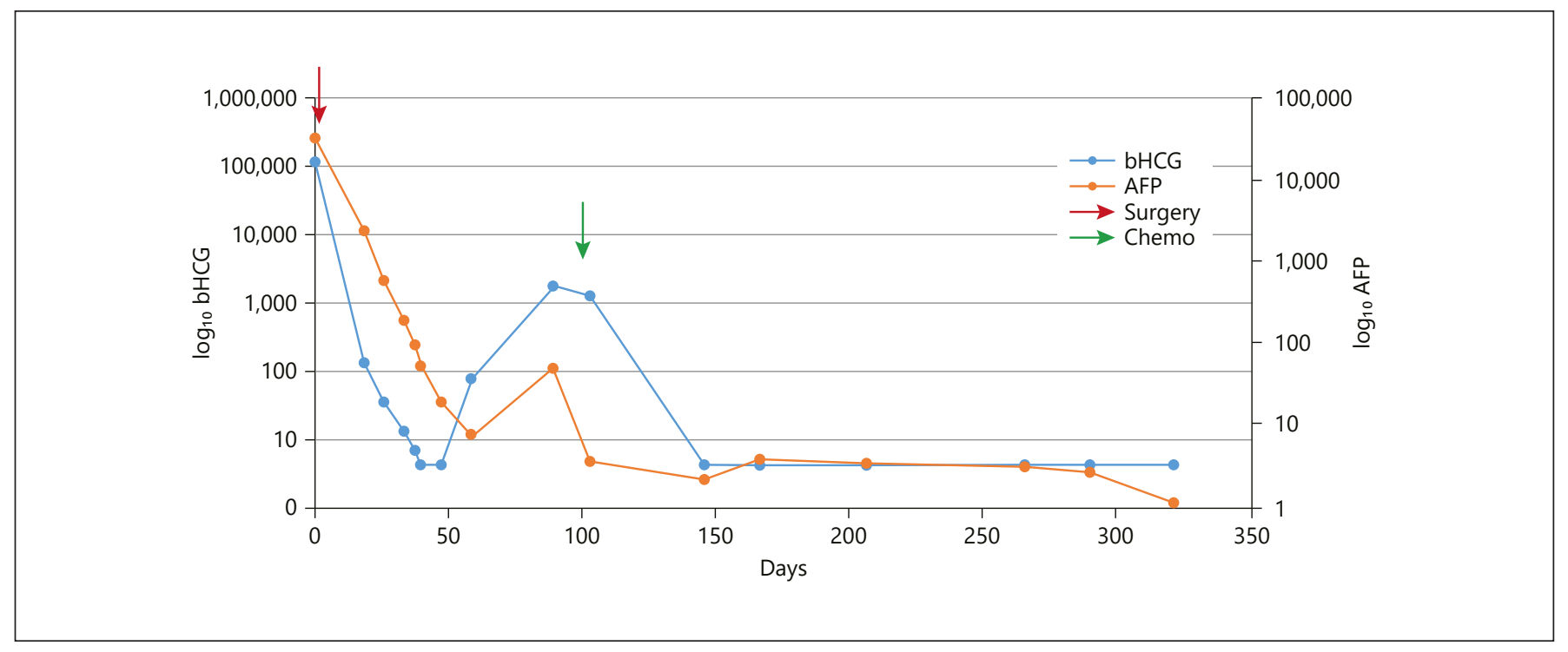

Fig. 3. Graph showing fall in tumor markers after tumor resection. 


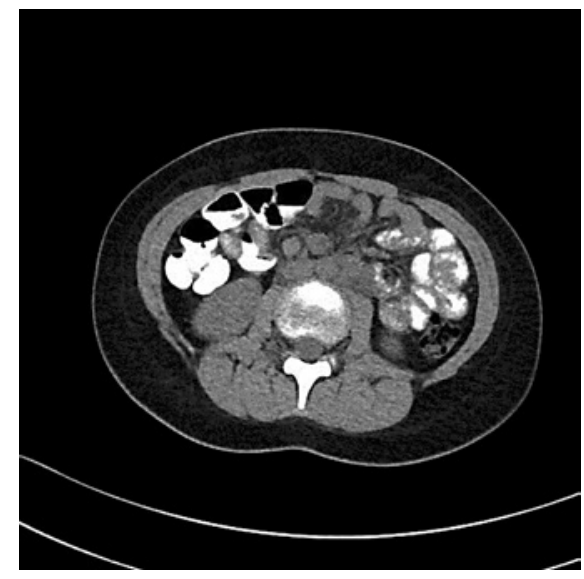

Fig. 4. Abdominal CT 3 months postsurgery.

germinoma with yolk sac tumor, unlike our case, which showed a mixture of embryonal carcinoma and yolk sac tumor. It is essential to know the quality and quantity of the components as a guide to a specific therapeutic regimen [5]. Precocious puberty is defined as the onset of puberty before the age of 8 years in girls or 9 years in boys. PPP, which is gonadotrophin independent, is always pathological and can be caused by estrogen secretion. Our patient presented with thelarche at the age of 4 years and vaginal bleeding at the age of 7 years, which are clear signs of PPP due to excess secretion of estrogen from the malignant ovarian GCT. Abdominal distension, pain, and vomiting were mostly due to the pressure effect and displacement of bowel loops caused by the tumor. Diagnosis of GCT is based on clinical examination, imaging, and laboratory findings. Endocrinal evaluation was done as there were signs of PPP. This evaluation included a bone age $\mathrm{X}$-ray study to know the maturity status of the bone growth plates and to guide through growth hormone therapy, thyroid function test, as severe primary hypothyroidism may lead to precocious puberty [6], and LHRH stimulation test to exclude any central cause of precocious puberty. The surgery, being a unilateral left-sided salpingo-oophorectomy, allows future fertility preservation and was followed by a thorough inspection of the abdomen, lymph nodes, and contralateral side. Based on postoperative staging (1a), a "watch and wait" strategy was chosen, particularly as the tumor markers dropped dramatically after salpingo-oophorectomy and as there is a $75 \%$ chance of avoiding chemotherapy with close monitoring.

At 3 months postsurgery the child's tumor marker started increasing (AFP $47.6 \mathrm{IU} / \mathrm{mL}$ ), for which initiation of chemotherapy was decided after re-staging assessment including a bone scan and a contrast CT of the chest, abdomen and pelvis. Apart from a few enlarged abdominal nodes, the rest of the scan was reported as normal.

Most patients with mixed ovarian GCTs are cured, but a small percentage develop recurrence, usually within 24 months of primary diagnosis.

It was decided to continue administration of Decapeptyl, a GnRH analog, as a means to preserve fertility by suppressing pituitary secretion of FSH and LH [7], and to prevent ovarian damage and premature ovarian insufficiency from chemotherapy toxicity [8]. Moreover, Decapeptyl injections would help to halt further pubertal changes, but would not reverse the Tanner stage from an advanced score of 3-4, as in our case.

Our patient is on regular follow-up with pediatric oncology and endocrinology in Dubai Hospital.

\section{Conclusion}

Mixed GCT, a very rare, highly malignant tumor, has never been reported before from the United Arab Emirates. Multidisciplinary team management consisting of careful initial surgery with adequate staging biopsies followed by combination chemotherapy and endocrinological evaluation and treatment can greatly improve the prognosis of these patients, as was seen in this child's management at Dubai Hospital.

\section{Statement of Ethics}

Signed consent was obtained from the patient's family.

\section{Disclosure Statement}

The authors have no conflicts of interest to declare.

\section{Funding Sources}

There were no funding sources.

\section{Author Contributions}

All authors contributed equally to this report. 


\section{References}

1 Cancer Research UK. Germ cell tumours [cited 2019 March 9]. Available from: https:// www.cancerresearchuk.org/about-cancer/ germ-cell-tumours.

2 Gershenson DM. Ovarian germ cell tumors: pathology, epidemiology, clinical manifestations, and diagnosis. Goff B, Pappo AS, Garcia RL, Barss VA, editors [cited 2019 March 9]. Available from: https://www.uptodate.com/ contents/ovarian-germ-cell-tumors-pathology-clinical-manifestations-and-diagnosis.
3 Kaplowitz PB. Precocious puberty: background, pathophysiology, epidemiology [cited 2019 October 24]. Available from: https:// emedicine.medscape.com/article/924002overview.

4 von Allmen D. Malignant lesions of the ovary in childhood. Semin Pediatr Surg. 2005 May; 14(2):100-5. Available from: https://www. ncbi.nlm.nih.gov/pubmed/15846566.

5 Rana S, Gill MK, Kalhan S, Satarkar RN, Sangwaiya A, Singh P. Immature teratoma with embryonal carcinoma; a rare malignant mixed germ cell tumor in a 13-year-old girl. Iran J Pathol. 2016 Winter;11(1):66-70. Available from: https://www.ncbi.nlm.nih. gov/pmc/articles/PMC4749198/\#B3.
6 Marcdante K. Nelson essentials of pediatrics. Philadelphia (PA): Elsevier/Saunders; 2015.

7 Di Tucci C, Casorelli A, Morrocchi E, Palaia I, Muzii L, Panici PB. Fertility management for malignant ovarian germ cell tumors patients. Crit Rev Oncol Hematol. 2017 Dec; 120:34-42.

8 Appelbaum HL. Abnormal female puberty [cited 2019 October 25]. Available from: https://link.springer.com/book/10.1007\% 2F978-3-319-27225-2. 